\title{
The Experience of Guided Online Therapy: A Longitudinal, Qualitative Analysis of Client Feedback in a Naturalistic RCT
}

\author{
Jacinta Jardine1, Caroline Earley ${ }^{1,2}$, Derek Richards ${ }^{1,2}$, Ladislav Timulak ${ }^{2}$, Jorge E Palacios ${ }^{1,2}$, \\ Daniel Duffy ${ }^{1,2}$, Karen Tierney ${ }^{1}$, Gavin Doherty ${ }^{3}$ \\ ${ }^{1}$ SilverCloud Health, Dublin, Ireland (jacinta.jardine, caroline.earley, derek.richards, jorge.palacios, \\ daniel.duffy, karen.tierney)@silvercloudhealth.com \\ ${ }^{2}$ School of Psychology, Trinity College Dublin, Dublin, Ireland. Ladislav.Timulak@tcd.ie \\ ${ }^{3}$ School of Computer Science and Statistics, Trinity College Dublin, Dublin, Ireland. \\ Gavin.Doherty@tcd.ie
}

\begin{abstract}
Internet-delivered Cognitive Behavioural Therapy (iCBT) is an effective treatment for depression and anxiety disorders. However longitudinal qualitative research into the client's subjective experience of this form of treatment 'in the wild' is relatively scarce. We present an analysis of secondary outcomes in a naturalistic RCT conducted within the UK's Improving Access to Psychological Therapies programme. We evaluated clients' expectations, experience, and context of usage of iCBT, across three timepoints. Results are discussed in terms of the creation of a therapeutic space online, the impact of hope, expectations and personal factors on the therapeutic experience, iCBT as "therapy on the go" and developing skills for life. While iCBT on the whole provides a positive, supportive and therapeutic experience for clients, the study identified managing expectations, polarized preferences, momentary help-seeking and longterm support as important aspects of the experience to consider in future design.
\end{abstract}

\section{Author Keywords}

iCBT, user experience, mental health, longitudinal study

\section{CSS Concepts}

- Human-centered computing Empirical studies in HCI

\section{INTRODUCTION}

Mental ill health is an accelerating societal concern; recent research on the global burden of disease indicates that psychological and mood disorders are a leading cause of years lived with disability, and match cardiovascular and circulatory diseases in terms of disability-adjusted life-years [72]. Depression and anxiety are two of the most common mood disorders, currently constituting the highest proportion of disability amongst all mental and substance abuse disorders [75].

\footnotetext{
Permission to make digital or hard copies of part or all of this work for personal or classroom use is granted without fee provided that copies are not made or distributed for profit or commercial advantage and that copies bear this notice and the full citation on the first page. Copyrights for third-party components of this work must be honored.

For all other uses, contact the Owner/Author.

CHI '20, April 25-30, 2020, Honolulu, HI, USA

(C) 2020 Copyright is held by the owner/author(s).

ACM ISBN 978-1-4503-6708-0/20/04.

https://doi.org/10.1145/3313831.3376254
}

Traditional treatment options for depression and anxiety include medication and psychological therapies, with both showing comparable outcomes [10], although clients typically prefer psychological over pharmacological treatments [41]. Psychological therapies such as Cognitive Behavioural Therapy (CBT) have been shown to be both clinically and cost effective [44] in the treatment of anxiety and depression, however numerous systemic and individual factors prevent people from accessing evidence-based interventions in the real world, including long waiting lists (due to high demand and a shortage of trained clinicians), stigma, personal time constraints, high costs and transportation problems $[35,43,79]$.

In order to address these concerns and make efficient use of the resources available, services have moved towards adding online interventions as alternative treatment methods, particularly for clients presenting with milder symptoms. These interventions, which are often based on CBT due to its suitability for an online delivery format (i.e. highly manualised and structured format), provide an alternative to face-to-face treatment sessions, delivering more treatment with available staff and increasing overall access to care $[13,50]$. An issue that emerged early in the development of online interventions was attrition, or nonadherence to treatment, which was particularly concerning considering the dose-effect relationship present [33]. To mitigate this, modern interventions usually include some aspect of therapist support, which can be face-to-face, via written message/email or phone contact; human support has been shown to be a key moderator in online intervention effect sizes [78]. There is an extensive body of research to date demonstrating the effectiveness of online interventions in the treatment of depression and anxiety disorders [45,78].

The design and evaluation of these interventions has recently become an area of interest in HCI research, particularly in light of broader concerns around how technology can be used to support psychological wellbeing and optimum human functioning $[3,8,49]$. Online mental health interventions have complex and specific design requirements due to the sensitive nature of the interactions and the content involved, 
and the client's state of mind. While there are structural obstacles to incorporating client perspectives which should be acknowledged and addressed in initial design efforts [3], there remains a need to understand how clients engage with and experience online treatments in the real world, in order to inform the design and delivery of these interventions.

In this paper we explore qualitative client feedback on the use of online interventions for depression and anxiety, gathered as part of a large-scale Randomised Controlled Trial (RCT) conducted in a routine public health care setting within the UK's Improving Access to Psychological Therapies (IAPT) programme [52]. Within this study we examined clients' expectations of online treatment, their experience of it and when and how they used the intervention. To gain an understanding of how these experiences change over time, we collected data at baseline (pre-treatment), midpoint (4 weeks into treatment) and posttreatment (8 weeks).

The study contributes a longitudinal understanding of the experience of guided online therapy, covering expectations, challenges and insights captured during the experience of treatment, and reflective perspectives on integration and personal change afterwards. The findings directly inform a number of directions for future research and design efforts.

\section{BACKGROUND}

\section{What is experience?}

Experience refers to transactions between us and the objects and events that make up the world in which we act [40].

Experience is an individual, internal and often impenetrable phenomenon, which numerous different fields have explored in an effort to define or understand it more clearly. McCarthy and Wright's framework of experience [40], which is strongly informed by pragmatist philosophy and the works of John Dewey [11], explores experience in terms of its composition, its sensory, emotional and social components, the space and time within which it exists and its historical context [40]. All of these factors shape our experiences, and each experience in turn shapes our context, history and future; our lives and selves are inexplicably entwined with our experiences. We perceive the world from our own perspectives, which are not just unique to each person, but to each situation and time that person finds themselves in [14]. Experience can be seen not as a singular phenomenon, but a multi layered one that changes over time, reflecting the various ways we can interpret our lives and our states of consciousness, i.e. our multiple selves [14]. Much of the research in this area fits within two major categories of experience - the momentary, hedonic sense of 'what I am experiencing right now', and the more retrospective or prospective narrative version of experience.

Momentary experience is in a sense a concrete world, where things are touched, seen or heard with the senses directly, but it is fleeting in nature [2]. This type of experience is for the most part an inattentive stream of consciousness and sensation, it is the flow of everyday life. On the other side of momentary experience are the more bounded types of mindful or aesthetic experiences, which are marked by beginnings and ends, and a sense of engaged awareness of what is taking place $[11,20]$. Experience can also been seen as the story that we tell ourselves, the narratives through which we remember past experiences and imagine future ones [60]. This type of experience is essential to our selfidentity, because it is through these stories that we make sense of ourselves and our lives [67]. Our narrative experience is entwined with our idiosyncratic systems of encoding and recollecting memories [71,73]; how we selectively remember and interpret our experiences allows us to alter them after the fact, which is a powerful force in shaping our lives [30,40,48]. This narrative moulding even extends into experiences that haven't occurred yet, where we see that anticipation or expectation of an experience plays a part in continually forging and adapting the experience as it is happening [40]. Hence examining these three levels anticipation of experience, experience in the moment and recollections of experience, can help us to gain a holistic picture of a person's experience, that speaks not just to one aspect of their identity, but to their many varied selves.

\section{Experience of technology}

When looking at user experiences of technology. design researchers have also explored the concept of varied selves, distinguishing between experience as hedonic, momentary, sensual perception and experience as instrumental, retrospective or based on self-narrative [14,24,31,39,70]. Another area explored by HCI researchers is the temporality of the experience of technology and how experiences change over time. User acceptance is not seen as an singular occurrence, but rather as a process that migrates and changes as the technology is embraced [19,57]. Karapanos et al. offer a model of user experience that includes phases of orientation, incorporation, and identification in the adoption of technologies over time [31], in line with results from Magni et al, who found that hedonic factors in the intention or motivation to use a product decrease and instrumental factors increase over time [39]. Thus time is a significant factor in how we experience and assess technology.

Expectation and anticipation are another key factor in a user's experience of technology. The pre-determined ideas and concepts we hold about a particular piece of technology shape our real experience of it. But expectation is not just an a priori event that affects our experience, it can be seen as an integrated and essential part of it [31]. Overall, this research indicates that a user's unique experience of technology is one that occurs both sensorially in the moment and as a part of their adapted self-narrative, it fluctuates and changes over time and it is affected by their expectations [14].

\section{Experience of therapy}

This already rich picture becomes more complex when we come to consider the client experience of therapy. In a recent qualitative meta-analysis of client experiences of 
psychotherapy, Levitt et al. found that clients tend to experience therapy as a process of integrative and systemic change, with a number of factors influencing their experience, including the capacity to build a caring, trusting and collaborative relationship with the therapist, the client's level of agency in the process and the suitability of the therapy to the client's needs [37]. An earlier meta-analysis explored client experiences of helpful events (e.g. selfawareness/insight, behavioural change/problem solution, empowerment, relief, feeling understood) and helpful impacts in psychotherapy (e.g. new perspectives, new behaviour, new experiencing and motivation), interestingly finding the same processes and impacts across different therapeutic approaches [68]. This implies that the key experiential ingredients of therapy are comparable across therapeutic approaches, so the question then becomes, are they comparable across delivery formats?

\section{Experience of online therapy}

Online therapy as a field draws on concepts from psychotherapeutic practice in an attempt to bring some of the therapeutic qualities of traditional therapy into the digital sphere [49]. Helpful aspects of online interventions reported by clients include the provision of information, learning therapeutic skills and techniques, autonomy and flexibility, and therapist support $[7,16,21,46,51,61]$. These features lead to experiences of feeling supported, validated, reassured, relieved and empowered, and more pragmatic experiences of gaining self-awareness and insight, behavioural change and crucially, seeing an improvement in mood or a reduction in symptoms [7,16,36,46,51]. The convenience, accessibility and flexibility of online treatment is particularly significant when compared with traditional face-to-face therapies, which consist of structured, time-bound appointments [49]. The freedom of accessing online interventions independent of time or location can create a less stressful experience for clients, who can also feel stimulated by the responsibility placed on them in this self-regulated form of treatment [27].

Unhelpful aspects of treatment identified in the literature include program content that is not tailored to individual needs, technical accessibility or usability issues, privacy concerns, the amount of work involved and inadequate support or generic therapist feedback [7,16,46,51,54,76]. These factors lead to experiences of frustration, irritation, isolation, confusion, feeling under pressure, self-criticism and increased anxiety or low mood. Other factors extraneous to the intervention have also been identified as hindering engagement and creating negative experiences of treatment. These include personal motivation (which is often linked to depression factors such as apathy, low self-esteem and difficulty concentrating), lack of computer/internet skills (or conversely technology fatigue from using a computer at work), a desire for human contact, negative attitudes towards technology/online self-help, a lack of belief in the effectiveness or applicability of the treatment, distractions/a lack of privacy, competing priorities and time constraints $[7,15,22,27,51,57,61]$.

\section{Expectations of online therapy}

Another area of relevance to the client's experience of online therapy, as with technology, is their expectations. The one crucial expectation that has been shown to mediate outcomes and adherence to treatment is the expectation that the treatment will be effective $[9,17,46,49]$. A reason for this could be that high expectations lead to early engagement and uptake, a factor linked to more persistent adherence [62]. The specific expectations clients have about online therapy are often affected by their prior knowledge and understanding of the format of traditional therapies. These expectations can include those related to therapist contact, e.g. that it will be difficult to form a trusting, meaningful relationship online and this will lead to a lack of accountability, or conversely that the anonymity of online treatment will aid their commitment and make it easier to be honest [4].

\section{Hope and readiness for change}

Two influential elements closely linked with expectations are hope for recovery and readiness for change. Snyder's Hope Theory [63] sets out that hope is a positive motivational state based on a client's perceived agency and capacity to move towards a predefined goal, combined with their belief in the effectiveness of their chosen pathway towards that goal. Thus hope in light of an online intervention inherently involves belief in the effectiveness of the treatment, but is also composed of other intrinsic factors such as the desperation of living with mental illness, the desire to feel better, and having an internal locus of control $[49,76]$. Hope can also stem from taking the initiative to actively engage in treatment, which can be highly motivating for clients who might have felt out of control and ineffective for years [76].

Readiness for change relates to the Transtheoretical Model (TTM), which conceives behaviour change as a process that unfolds over time as a person moves through six stages, e.g. no intention to change, contemplating change, preparing to take action, taking action, maintenance of change and no risk of relapse [47]. Along with the stages of change the TTM also posits processes of change, such as consciousness raising about the causes, consequences, and cures for a particular problem behaviour, belief in the ability to change and the commitment to act on that belief [47]. Readiness to change is not a static trait, but rather a fluctuating product of awareness, motivation, agency, hope, social influences and interpersonal interaction, among other factors [58]. A client's position in the stages of change can have a significant impact on their subsequent acceptance of and experience with an online treatment [76].

\section{A gap in our knowledge}

Despite the body of research presented here, researchers have called for further in-depth qualitative exploration of client experiences of online therapy $[34,38,46,57,67]$ as there are still a number of gaps in our understanding of this unique setting. One area that has not been explored in the data is how client experiences and expectations change over time. As we have shown, experience is largely temporal, composed of composite self-identities and shaped by expectations. 
Examining all of these aspects is therefore crucial in gaining a holistic understanding of the experience of online treatment for the client. Capturing experience data at the time of usage will help to prevent recall bias and increase the chances of capturing the momentary experience [49], yet post-treatment retrospective perspectives also form a key part of a person's experience and should therefore be taken into account. Incorporating diverse, temporal perspectives into our understanding of client experiences will bring a richness and depth to our knowledge that is scarce in the current literature. Furthermore there are few clinical HCI studies in this area to date [59], and many of the studies discussed previously were not in routine care settings or in 'the real world' per se. As the data suggests, experience and usage vary between exploratory trials and real world settings; understanding how these treatments are implemented in practice and how clients perceive online therapy within natural implementation systems, has therefore been marked as one of the core challenges in digital health today $[18,34]$. This study is also interdisciplinary in nature, and thus contributes to bridging the divide between HCI and Health research, a concern regarded as integral in improving the utility and quality of future digital health intervention research [5].

\section{The current study}

The current study sought to explore the nature of clients' experiences of an online intervention for depression and anxiety in a natural, routine care setting.

To this end, the research questions we asked were:

- What are people's expectations of iCBT and how do these change over time?

- What are people's experiences of iCBT?

- What is the context of people's use of iCBT? (when, where and how do they use it)

\section{METHOD}

\section{Study Design}

This study was an analysis of secondary outcomes in a largescale RCT conducted in a routine care, public health service setting. Open-ended survey data were collected via the intervention platform at baseline (pre-treatment, T1), midpoint (4 weeks, T2), and at the end of the 8-week treatment (T3).

\section{Measures}

We designed an open-ended therapeutic experience questionnaire for the purpose of this study, which comprised of 10 questions exploring clients' expectations of their online treatment, their experience of the intervention, the context of their use of the intervention and their perception of the aesthetics employed (see online appendix).

\section{RCT Design and Setting}

The main study was a parallel-groups RCT examining the effectiveness and cost-effectiveness of iCBT interventions for depression and anxiety disorders, against a waitlist control group. The study was conducted within the UK's public health service, the NHS (National Health Service), through their IAPT programme. IAPT is designed to provide a stepped care approach to treating people with anxiety and depressive disorders. As recommended by the National Institute for Health and Care Excellence (NICE) [44] the IAPT programme offers iCBT as a low-intensity, step 2 intervention for individuals presenting with mild to moderate symptoms of depression and/or anxiety.

This study was conducted in the IAPT service of Berkshire Healthcare NHS Foundation Trust. The intervention used (SilverCloud $[13,53]$ ) has been delivered to tens of thousands of clients in this service, as it forms a routine part of the care pathway. For the clinical supporters in the study (Psychological Wellbeing Practitioners, or PWP's), supporting clients on the intervention is part of their normal workload. Clients were recruited for the study through the normal referral pathway of this service; all adult users of the Berkshire IAPT Talking Therapies Step 2 services were approached to participate and measured against set eligibility criteria [52]. Suitability for an internet intervention was assessed based on the willingness of the participants to engage in the $\mathrm{iCBT}$ intervention, presence of mild to moderate levels of anxiety and depression, having internet access and no suicidal intentions, self-harm risk, psychotic illnesses or current psychological treatments. The trial received ethical approval from the NHS England Research Ethics Committee (IRAS ID: 214669). Clients were assessed for risk at baseline, in line with routine clinical practice, and monitored for risk throughout their treatment with the help of risk measures embedded in the platform.

\section{Platform Design}

Participants were assigned to one of the following programs: Space from Depression, Space from Anxiety or Space from Depression \& Anxiety. Programs that address specific anxiety disorder presentations (e.g. Social Anxiety, Health Anxiety) were also offered. All programs are delivered on a Web 2.0 platform using media-rich interactive content. The programs usually consist of 7-8 psychoeducational modules, delivered in a non-linear fashion, with each module taking roughly 40 minutes to complete. Treatment was supported by weekly asynchronous feedback from PWP's, either via written messages in the platform or by telephone appointment, as per the natural setting.

The four key design strategies for user engagement employed in the SilverCloud platform are interactive (tools, quizzes, list apps, interactive content, like and comment buttons), personal (personalised homepage and profile, bookmarking, personal key messages for each module, progressive release of tools over time), social (personal stories and accounts from other users, anonymous indications of other users via like buttons and content suggestions) and supportive (regular therapist support, user can 'share' content with their supporter which makes their contact more relevant and personal). See the multimedia 
appendix and the original research paper [13] for further details of the intervention design.

\section{Participants}

Of the 361 participants randomised in the trial, 256 completed at least one question on the therapeutic experience questionnaire and 183 completed all ten questions. Due to the large volume of data collected and our desire to look at both expectations and experience, only participants for whom we had complete data were included in the current study sample. The included records were selected at random from the research completers. After reaching saturation, the final number in our study sample was 100 participants.

\section{Data Analysis}

Data were analysed using the descriptive-interpretive method [69]. The first step in the analysis involved the first author familiarising themselves with the data by reading the entire dataset, making notes, and conducting a detailed examination of 10 randomly selected cases (a case here refers to all the data from one participant). All authors have previous experience analysing qualitative data. The data were divided into four key domains of investigation (Expectations, Experience, Context and Aesthetics), to fit how the data were collected through the therapeutic experience questionnaire. The aesthetics domain is not included in the analysis, as responses to the aesthetics question (How would you describe the appearance of SilverCloud?) had little depth and brought no new insights.

The initial 10 cases were then coded in NVivo 12. Within the four domains, the data were clustered according to similarities and thus themes were created. The $4^{\text {th }}$ author provided feedback on the analysis, and a further 50 randomly selected cases were coded; further themes and sub-themes were created, sorted and merged in accordance with the data. A taxonomy of the domains, themes and subthemes was developed and presented to the other authors for review and feedback. A consensus was reached on how to organise the data, and the taxonomy was adjusted accordingly. A further 40 cases were analysed, and saturation was deemed to have been established as no new themes emerged and it was possible to place all the data within the existing taxonomy. The entire coded dataset (100 cases in total) was given to the $2^{\text {nd }}$ author to audit for fidelity.

As responses to the 10 therapeutic experience questions were grouped under only 4 domains, some of the domains included more than one question response from each participant. This meant there were often multiple references from the same participant under each theme or subtheme. Matrix coding queries were thus run to determine the number of participants coded under each theme and sub-theme, rather than the number of references. These are the figures that appear in the results tables.

\section{RESULTS}

The findings will be presented across three domains: Expectations of Online Treatment (including 3 sub-domains of General Expectations, Practical Expectations and Experience vs. Expectations), Experience of Online Treatment and Context of Usage.

\section{Expectations of Online Treatment}

Some general findings within this domain relate to language use and the difference between hopes/desires and expectations. Across the entire sample of 100, 52 clients used the word hope when answering the questions related to their expectations of treatment. The decision was made not to distinguish between hope and expectation in the taxonomy as many clients who did not use the word hope had hopeful/positive expectations for treatment. Despite this we felt that it was an interesting finding.

\section{General Expectations}

Four themes were grouped under this domain: Expecting personal development, Expected benefits of the online treatment, Expected challenges with online treatment and Other expectations (see Table 1).

\begin{tabular}{|c|c|c|c|}
\hline$\%$ & Themes & $\%$ & Subthemes \\
\hline \multirow[t]{6}{*}{90} & Expecting & 75 & Develop self-management skills \\
\hline & personal & 28 & Develop insight and understanding \\
\hline & development & 22 & Build hope for the future $\&$ a \\
\hline & & 17 & Build confidence and be \\
\hline & & & empowered \\
\hline & & 15 & $\begin{array}{l}\text { Improve health, relationships \& } \\
\text { mood }\end{array}$ \\
\hline \multirow[t]{4}{*}{42} & Expected & 21 & Experience will be supportive \\
\hline & $\begin{array}{l}\text { benefits of } \\
\text { online }\end{array}$ & 15 & $\begin{array}{l}\text { The platform will be convenient } \\
\text { and easy to use }\end{array}$ \\
\hline & treatment & 8 & $\begin{array}{l}\text { Experience will be less demanding } \\
\text { than other therapies }\end{array}$ \\
\hline & & 8 & Generally high expectations \\
\hline \multirow[t]{2}{*}{41} & Other & 26 & Not sure what to expect \\
\hline & expectations & 17 & $\begin{array}{l}\text { The platform will be like an } \\
\text { online/educational course }\end{array}$ \\
\hline \multirow[t]{2}{*}{23} & $\begin{array}{l}\text { Expected } \\
\text { challenges }\end{array}$ & 17 & $\begin{array}{l}\text { Experience will be } \\
\text { challenging/strange }\end{array}$ \\
\hline & $\begin{array}{l}\text { with online } \\
\text { treatment }\end{array}$ & 6 & Experience could feel disconnected \\
\hline
\end{tabular}

\section{Table 1. General Expectations}

\section{Expecting personal development}

This theme reflects the expectations clients had of themselves and their own self-development through use of the intervention. This was the most prevalent theme under the domain of General Expectations, with $75 \%$ of clients expecting to develop self-management skills and learn how to practically deal with their condition/emotions/thoughts through use of the intervention. Clients also expected to develop insight and understanding, to feel better and see an improvement in their health, relationships and mood, to build hope for the future and a positive outlook, and to build their confidence and be empowered by the intervention.

\section{Expected benefits of online treatment}

42 clients had high or positive expectations of the treatment itself, for example 21 clients reported that they expected to 
feel supported, understood and cared for via the online treatment. A further 15 expected it to be convenient and easy to use due to it being accessible in their own time, under their control, immediately accessible and able to integrate seamlessly into their lives, 'Will feel good knowing there is online support that I can access at any time without having to wait for appointments'(T1). Clients also expected the online format to be less demanding than other therapies, i.e. less pressure than having to see someone face-to-face, ' $I \mathrm{am}$ uncertain but I like that I am able to access the system discreetly and privately to consider what I am doing in a stress free environment'(T1).

\section{Expected challenges with online treatment}

$23 \%$ of clients had negative expectations of the treatment. Some expected the experience to be challenging, emotionally confronting or feel strange or alien, while others expected online treatment to feel disconnected or cold when compared to face-to-face therapy. For some there was an understanding that the treatment would feel challenging, but this was a necessary part of engaging in therapy, e.g. 'Emotional but cathartic'(T1), 'Challenging but in a good way' (T1) or that the self-driven nature of the therapy could be taxing, 'Difficult at times as it will need my own energy and dedication to be effective'(T1).

\section{Practical expectations}

This domain relates to clients' expectations of when they will use the platform. Data under this domain were grouped into four themes: Time dependent usage, Mood dependent usage, Situation dependent usage and Not sure what to expect (Table 2).

\begin{tabular}{llrl}
$\mathbf{\%}$ & Themes & $\mathbf{\%}$ & Subthemes \\
\hline 56 & Time dependent & 38 & At a specific/routine time \\
& & 13 & Regularly \\
& & In free time \\
\hline 56 & Mood dependent & 50 & When feeling low \& in \\
& & 8 & Weed of help \\
& & 15 & When feeling okay \\
\hline 15 & Situation dependent & 15 & Whot distracted \\
\hline 7 & Not sure what to expect &
\end{tabular}

Table 2. Practical Expectations

Time dependent usage

$38 \%$ of clients expected to use the online treatment at a specific or routine time (e.g. mornings, evenings, before bed). A smaller number expected to use it in a more ad hoc and less routine manner, i.e. whenever they had free time or could fit it into their schedule. A few clients stated that they expected to use the platform frequently, or as much as possible.

\section{Mood dependent usage}

$50 \%$ of clients expected to use the platform when they were having a bad day, feeling low or anxious, or were in need of help or support. Other clients however, expected to only use the platform when they were in good or calm moods.

\section{Experience vs. Expectations}

This domain is based on the question "How has your experience of SilverCloud compared to your initial expectations?" asked at the midpoint of treatment. Three broad themes emerged: Experience of treatment exceeded expectations, Experience of treatment met expectations and Experience of treatment was less than expected (Table 3).

\section{Experience of treatment exceeded expectations}

$39 \%$ of clients reported that their experience of online treatment was better than they expected it to be. While many clients did not provide a reason for this, those that did reported that it was more helpful (e.g. more interactive/practical or more educational) than they expected, or easier to use, more convenient, or more supportive than they expected:

'When I first started I thought I'd be working through the programme on my own without any support but I was wrong! It's really nice to know you have a therapist you can ask questions and help you with the programme'. (T2)

\section{Experience of treatment met expectations}

There was a sense here that the intervention was well introduced to the client, and also a general positive trend within this theme around positive expectations or hopes being met:

'I have been very happy with the websites, advice, guidance, meditation exercises and the fact that they are available to download so that I am able to use them when I need them. It has fully met what I hoped it would be'. (T2)

\section{Experience of treatment was less than expected}

$6 \%$ of clients felt that their experience of online treatment was generally harder than they expected (e.g. more stressful/tiring or harder to form a routine or remember to engage than expected). Others expected the therapist contact to be more helpful/therapeutic, or the treatment to be more practical, interactive or structured:

'I suppose the online programme is not quite as structured as I expected - its not always $100 \%$ clear to me what I should be doing on a day-to-day/ week by week basis.' (T2)

\begin{tabular}{|c|c|c|c|}
\hline$\%$ & Themes & $\%$ & Subthemes \\
\hline 39 & $\begin{array}{l}\text { Experience of } \\
\text { treatment } \\
\text { exceeded } \\
\text { expectations }\end{array}$ & $\begin{array}{l}12 \\
5\end{array}$ & $\begin{array}{l}\text { Generally better/more helpful } \\
\text { than expected } \\
\text { Easier to use/more convenient } \\
\text { than expected } \\
\text { More supportive than expected }\end{array}$ \\
\hline 28 & $\begin{array}{l}\text { Experience of } \\
\text { treatment met } \\
\text { expectations }\end{array}$ & $\begin{array}{l}16 \\
8 \\
5\end{array}$ & $\begin{array}{l}\text { Generally as expected } \\
\text { Too early to tell } \\
\text { Unsure what to expect }\end{array}$ \\
\hline 11 & $\begin{array}{l}\text { Experience of } \\
\text { treatment was less } \\
\text { than expected }\end{array}$ & 6 & $\begin{array}{l}\text { Generally harder/less helpful } \\
\text { than expected } \\
\text { Less interactive than expected }\end{array}$ \\
\hline
\end{tabular}

Table 3. Experience vs. Expectations

Experience of Online Treatment

Eight main themes were identified under this domain: Experiencing personal development; A positive, calming 
experience; A personal, supported experience; Platform is straightforward \& educational; Feeling empowered \& in control; Challenges with treatment, Engagement issues and Feeling emotionally strained (see Table 4).

\section{Experiencing personal development}

This theme reflects the experiences clients had of selfdevelopment through use of the online treatment. As with the corresponding theme under the General Expectations domain, this was the most prevalent theme under the Experience domain, however only $36 \%$ of clients reported developing self-management skills (compared to the $75 \%$ who expected it), one client stated, 'One thing I would personally like, is more tasks/examples to reinforce methodologies. But this is the way I learn I think'(T2). Clients also reported developing insight and understanding and gaining hope for the future and a positive outlook:

'SilverCloud has helped me to give thought to the way I look after my mental wellbeing by recognising what regular activities help me to be in a more confident mental place' (T3)

A positive, calming experience

$51 \%$ of clients stated that their overall experience of using the platform was a positive, enjoyable or pleasant one. Of those 51,8 clients reported that using the platform was a calming, private or reflective experience, while to a further 8 it felt like a freeing or even lifesaving experience.

\section{A personal, supported experience}

The majority of statements under this theme related to feeling connected (i.e. not feeling alone or feeling like others are going through similar things), as well as feeling supported, comforted or reassured by the experience of online treatment. References were also made to the therapist contact being helpful or motivational, and the platform feeling personalised or tailored to the client's individual needs. There was a sense that use of the intervention was a private and personal experience for clients, 'The time using SilverCloud has felt like 'me time' but in a self care kind of way. '(T3)

\section{Feeling empowered \& in control}

For more than a third of clients in this sample, the flexibility and autonomy of online treatment were significant positive factors in their experience. Being able to access the treatment in their own time and on their own terms helped clients to feel in control and engaged in their treatment. Clients also reported feeling empowered by taking proactive steps and being able to help themselves to feel better:

'I have enjoyed the feeling of 'self-teaching' as it were as it is me that is reading the information rather than somebody telling me what to do. I feel in control.' (T2)

\section{Challenges with treatment}

31 clients reported challenges with online treatment, which are interestingly the inverse of some of the positive themes mentioned above. Some clients felt that the treatment lacked adequate support and guidance, while others felt that the platform was difficult to use or the content was repetitive or not tailored to their individual needs. A small number expressed specifically that the treatment helped them to gain insight and understanding, but lacked the practical solutions needed to help them deal with their issues and feel better. For some the experience was initially challenging, but got easier with time, 'In the beginning I use to feel anxious and then as time passed I didnt feel scared using it' (T3), while for others the experience itself was difficult, but retrospective evaluation allowed them to see the benefits:

'I felt that it was difficult and wasn't helping the majority of the time, but in fact it really has because things have really changed, so I am glad I stuck with it.' (T3)

\begin{tabular}{|c|c|c|c|}
\hline$\%$ & Theme & $\%$ & Subtheme \\
\hline 65 & $\begin{array}{l}\text { Experiencing } \\
\text { personal } \\
\text { development }\end{array}$ & 45 & $\begin{array}{l}\text { Developing insight and } \\
\text { understanding } \\
\text { Developing self-management } \\
\text { skills } \\
\text { Gaining hope \& a positive } \\
\text { outlook }\end{array}$ \\
\hline 51 & $\begin{array}{l}\text { A positive, } \\
\text { calming } \\
\text { experience }\end{array}$ & $\begin{array}{l}43 \\
8\end{array}$ & $\begin{array}{l}\text { Overall positive experience } \\
\text { Using the platform is calming \& } \\
\text { reflective } \\
\text { Platform is a lifeline/ a relief }\end{array}$ \\
\hline 46 & $\begin{array}{l}\text { A personal, } \\
\text { supported } \\
\text { experience }\end{array}$ & $\begin{array}{l}16 \\
11\end{array}$ & $\begin{array}{l}\text { Feeling connected, supported \& } \\
\text { reassured } \\
\text { Therapist is helpful/motivational } \\
\text { Platform is tailored to individual } \\
\text { needs }\end{array}$ \\
\hline 43 & $\begin{array}{l}\text { Platform is } \\
\text { straightforward } \\
\text { \& educational }\end{array}$ & $\begin{array}{l}11 \\
10\end{array}$ & $\begin{array}{l}\text { Platform is easy to use \& } \\
\text { understand } \\
\text { Platform is informative } \\
\text { Platform feels like an } \\
\text { educational course }\end{array}$ \\
\hline 36 & $\begin{array}{l}\text { Feeling } \\
\text { empowered \& } \\
\text { in control }\end{array}$ & 17 & $\begin{array}{l}\text { Flexibility of platform aids } \\
\text { engagement } \\
\text { Self-driven aspect is } \\
\text { empowering }\end{array}$ \\
\hline 31 & $\begin{array}{l}\text { Challenges } \\
\text { with treatment }\end{array}$ & $\begin{array}{l}13 \\
13\end{array}$ & $\begin{array}{l}\text { Platform is difficult to use } \\
\text { Content is repetitive/not tailored } \\
\text { to individual needs } \\
\text { Needs more support \& guidance } \\
\text { Lack of practical help \& } \\
\text { solutions }\end{array}$ \\
\hline 22 & $\begin{array}{l}\text { Engagement } \\
\text { issues }\end{array}$ & 9 & $\begin{array}{l}\text { Flexibility of platform hinders } \\
\text { engagement } \\
\text { Lack of motivation hinders } \\
\text { engagement } \\
\text { Lack of free time hinders } \\
\text { engagement }\end{array}$ \\
\hline 20 & $\begin{array}{l}\text { Feeling } \\
\text { emotionally } \\
\text { strained }\end{array}$ & 12 & $\begin{array}{l}\text { Experience is emotionally } \\
\text { confronting } \\
\text { Feeling burdened }\end{array}$ \\
\hline
\end{tabular}

Table 4. Experience of Online Treatment

Engagement Issues

For $9 \%$ of clients the flexibility of the platform hindered their engagement with it; the lack of deadlines and structure meant it was easy to put off or forget about. Other more personal barriers to engagement included low motivation (due to low 
mood or otherwise) and a perceived lack of free time in which to use the platform.

\section{Context of Usage}

This domain focuses on when and how clients tended to use the platform. The four themes that arose under this domain were: Time dependent usage, Mood dependent usage, Situation dependent usage and Tool dependent usage (see Table 5). While the themes here are largely similar to what clients expected, an interesting difference to note is the generally higher numbers across this domain, compared to the practical expectations domain. Clients were evidently expecting to use the platform in one way, but actually using it in multiple ways, e.g. 'I tend to try and use it a bit every day so that I can progress gently but I do binge as well. '(T2)

\begin{tabular}{llll}
$\mathbf{\%}$ & Themes & $\mathbf{\%}$ & Subthemes \\
\hline 73 & Time dependent & 47 & At a specific/routine time \\
& usage & 40 & In free time \\
& & 15 & $\begin{array}{l}\text { Before/after a review or when } \\
\text { reminded }\end{array}$ \\
& & 5 & As much as possible \\
\hline 60 & Mood dependent & 43 & When feeling low \\
& usage & 20 & When feeling good/okay \\
& & 16 & When in need of help \\
\hline 23 & Situation & 23 & When alone/not distracted \\
& dependent usage & & \\
\hline 12 & Tool dependent & 7 & Mindfulness \\
& usage & 6 & Mood monitor \\
& & 7 & Other tools
\end{tabular}

Table 5. Context of Usage

\section{Time dependent usage}

Following closely with how clients expected to use the platform, the majority of clients used it at a specific or routine time. A higher number than expected (40\% compared to $11 \%$ ) used it whenever they had free time or could fit it into their schedule. An additional theme here related to the platform reminders and therapist support; $15 \%$ of clients reported using the platform when they were reminded, when certain content was recommended to them (after a review) or in preparation for their next review session with their therapist.

\section{Mood dependent usage}

In total 60 clients reported that their usage of the intervention depended on their mood. Of these, 43 clients reported using the platform when they were feeling low or anxious, and 16 when they were in need of help. A smaller number (20 clients) reported using it when they were feeling okay, calm, relaxed or in better moods. This is similar again to what was expected. Some clients stated that using the intervention would make them feel better or give them a boost, some reported that it made them feel worse in the moment, and for others it did both:

\footnotetext{
'I have noticed that I tend to use it on either very bad or very good days, not when I am feeling generally meh - which is most of the time. Sometimes I can find that it worsens my mood, other times it can improve it.' (T2)
}

Many clients were using the platform to actively change their mood, which increases self-efficacy and reinforces the client's belief in their ability to help themselves:

'Often when I am feeling stressed/anxious/down I log on because it is something I am actively doing to help myself.' (T2)

\section{DISCUSSION}

This study brings a number of insights into the experiences of clients accessing iCBT in a routine care setting. We found that expectations of self-development are high, and correspondingly, mid and post-treatment accounts of experiences are predominantly positive. This research reveals that the helpful events and impacts present in iCBT are similar to those found in traditional psychotherapy e.g. insight/awareness, behaviour change, empowerment, feeling understood [68]. Beyond this, there are a number of topics emerging from this research which have specific implications for the design of online interventions, including expectation management, usage pattern and mood state considerations, personalisation and longevity of use.

\section{Managing expectations}

Overall, the expectations of online treatment were high, with $90 \%$ of clients expecting to develop personally through use of the platform. A quarter of clients reported that they were not sure what to expect, but many of these clients had high hopes for insight or change through use of the treatment, despite their practical uncertainty. These results indicate that while there was variation in expectations, the majority of clients believed that they were capable of moving towards their goals, and had an expectation that the treatment would be effective, which are the key components of Snyder's Hope Theory [63] and important factors in mediating treatment outcomes $[9,17,46,49]$. These high expectations could account for the largely positive experiences clients had with the online treatment; showing the power of our narrative selves in constantly shaping the reality of our experiences.

For the most part the clients in this study expressed both hope for recovery and readiness for change (all fell within the 'Preparation' phase of the TTM, because they intended to take action within the next 30 days and had taken some behavioural steps in this direction [47]), as well as being well informed about what the treatment would entail, having high literacy about their condition and predominantly being suitable candidates for online treatment. These factors, which are a combination of personal and implementation elements, are all crucial to the intervention's effectiveness, yet they sit outside of the design of the intervention itself. In terms of implementation, examining the Berkshire IAPT service where this research was conducted could bring some insights into effective service design and implementation of online therapy, as the processes they have in place appear to be working well. Managing individual expectations, in this context, could involve introducing methods of increasing hope and readiness for change, such as Motivational Interviewing (MI) as a prequel to treatment $[42,58,74]$. 
This relationship between personal and implementation factors evokes the Design Tensions Framework [66], which looks at spaces in the design sphere where means, ways, and values come into conflict. Tensions are evolving relationships that allow us to explore continuums, dichotomies or opposing, disproportionate forces in the competition for limited resources. In circumventing the conventional problem/solution discourse, we can instead use design tensions to probe the multiple levels of problem formulation in these complex scenarios [66]. A design tension exists here between the current protocol of referring only 'suitable' clients to online interventions, and the concept of preparing clients so that the treatment becomes more suitable for them.

\section{Context of use}

A surprisingly high percentage of people reported using the platform as a coping mechanism for dealing with a range of symptoms related to low mood and anxiety, or as a way to find answers and seek help in the moment. This goes against the intended usage pattern for the intervention, which was designed around traditional therapy delivery, i.e. it is suggested that clients complete one module a week, taking approx. 40 minutes. One explanation for this usage pattern could be that low mood acts as a reminder for clients to use the platform, e.g. 'sometimes l forgot all about it as things were going well for me'(T3). Regardless of the reason, these results indicate that $\mathrm{iCBT}$ is a treatment delivery model that supports help seeking in the moment. Designers should be mindful that online interventions are commonly accessed during periods of low mood and used as a coping mechanism. Future designs could support mood regulation strategies that focus on current mood states, by providing insights about mood patterns and suggesting methods for improving mood (e.g. EmotiCal [64]). Automatic behavioral data sampling using sensors and existing phone data could also be used to track and predict low moods and provide more timely interventions [23].

Clients reported that they were also using the platform on a routine basis or at specific times during the day, i.e. use of the platform became a habit, something that was seamlessly integrated into the client's daily schedule. On the other hand a similar number of clients stated that they used the platform in their free time or whenever they had the chance, which signifies a more erratic usage pattern of therapy "on the go". It is clear that there is huge variance in usage patterns both between people (a finding in line with previous user experience research $[56,65]$ ) and within each person (most people were using the platform in more than one way). Mobile interactions and functionality should be leveraged to further facilitate these desired usage patterns. Shorter modules or sessions, ease and visibility of the ability to set reminders and ecological momentary interventions (EMI's) could be utilised on mobile to help make the most of having therapy "on the go" and to address engagement issues $[25,32]$. One client even suggested:
'I wonder whether the lessons could be broken down into smaller chunks that would then mean that someone could do 10-15 mins a day 3-5 days a week (depending on their modules)' (T2)

In encouraging further mobile usage we should consider the design tensions present. Potential negative impacts include dependence and isolation; these could be mediated via the design sensitivities of self-resilience and co-experience, i.e. promoting self and social engagement with the real world [1]. Furthermore, when incorporating EMI, flexibility and personal preferences should be accounted for, as not everyone can or prefers to engage in momentary interactions [56].

\section{Polarised preferences}

Our results indicate that some of the core features of iCBT (e.g. flexibility, autonomy, personalisation, support, level of information provision and interactivity) can be perceived as sufficient/insufficient or positive/negative by different people. In addition, use of the platform made some people feel worse in the moment, while for others it was reassuring and improved their mood; some people even stated that it could do either. The experience of iCBT is clearly a very personal one, and thus personalisation and tailoring are key implications emerging from this research, a finding again in line with previous design research [56]. Clients use the intervention in multiple different ways and find help across a diverse spread of features; diversifying treatments in terms of content delivery (e.g. media or audio as an alternative to text [28]), learning styles, socio-cultural factors (e.g. gender, social class, educational level, religion, race and ethnicity [12]), module progression and length, and even tone, could help to address a host of different issues that arise from providing the same treatment to disparate, unique individuals. The study illustrates specific aspects of interventions that might be targeted by efforts to support personalisation.

Design tensions come back into play here when we look at autonomy, flexibility, motivation and engagement as interdependent concepts that exist in a complex web of relationships, e.g. the responsibility inherent in the autonomy of online treatment is on one hand motivational, while on the other burdensome and stressful. Similarly the flexibility of online treatment is a hugely positive and enabling aspect for many people, yet it also appears to be a notable barrier to engagement. These results are in line with previous research findings $[15,27,34]$. Tatar talks of design tensions that are "good enough", i.e. some problems will never be solved, but by looking at them from the perspective of multiple levels of interacting tensions, we gain clarity on how to balance these tensions, rather than struggling to find a single (and likely fictional) solution [66].

\section{Skills for life \& long term support}

There is a sense in the data that many of the clients understand that they are gaining skills to help them stay well into the future, rather than simply treating an illness. They 
understand that this is long term work, e.g. one client stated 'I think the more often I use it, the more powerful/useful it will be' (T2), and another mentioned, 'I feel that it isn't just a 6 or 8 week course. It is going to take me a while to harness the techniques on here'(T3). One client even reported that the intervention felt for them like 'a reassurance of ongoing development'(T3). In a sense the intervention became almost like an extension of the self for many clients, it was a reflective, personal space that they could revisit and rely on. This relates back to Karapanos et al.'s model of user experience in the adoption of technologies, which posits that prolonged experiences become increasingly focused on the meaning of the product, the user's emotional attachment to it and how it fits into their life and self-image [31]. For some clients the intervention became so integrated into their lives that it migrated from the technology itself, e.g. 'I have downloaded the downloadable content to my phone so it is always with me'(T3), or:

'I have used the Worry Tree a lot. I have a laminated copy in my workbag. If my mind starts racing at work or at home I write my worries in my worry book then use I the Worry Tree' (T2)

Attachment and longevity of such interventions supports considering iCBT as a Positive Technology; we can see that the three levels of this theory, the hedonic (positive emotions), eudaimonic (self-empowerment) and social/interpersonal (connectedness), are all represented in the current study $[6,8,55]$. For the client, online interventions can be more like long-term, lifestyle support systems than "treatments". They currently exist within the paradigm of traditional therapies, yet this could be limiting their potential to fully provide for the client's needs, as we can see from this client's request:

'For me, I think for the next couple of months it would be good to check in with my sponsor once a month. I dont know if that is possible, but hoping it is. Just to keep me on track and also as it is such a big/hard thing to change the way you think' (T3)

While previous design guidelines suggest that interventions build on accepted theoretical models (e.g. CBT) in order to ensure clinical validity [12], this study together with previous HCI research $[36,65]$ indicates that incorporating non-CBT elements that support long-term wellbeing and growth, such as positive psychology, could be of benefit to clients. Furthermore different approaches, such as blended methods that provide m-health as an adjunct to therapy [56] or online support groups [36], and different types of technology interactions e.g. journaling, analyzing past experiences, and forecasting future moods [26,29] could all be explored to create a range of truly user-centered, effective interventions.

The design space for coping-strategies has been marked as an underdeveloped area in HCI [59]. By taking a broader temporal perspective on the experience of therapy, we see an opportunity for interventions to be delivered in more varied ways in the future, beyond the archetype of traditional therapies. By going beyond the "treatment" model we can also reach and benefit previously unsupported groups e.g. as a preventative measure for those at risk, or to facilitate thriving in those not currently experiencing mental health issues [77].

\section{FUTURE RESEARCH}

The clear next step for this research is to build on the analysis presented here by examining how individual clients change over time via a mixed-methods quantitative and qualitative trajectory analysis. We also plan to analyse and compare the non-complete records which were excluded from this study. Further research could explore the difference between hopes and expectations by posing these as separate questions, and include questions based on motivation and stages of change to ascertain their effect on expectations and experiences. Furthermore, due to the difficulty uncovering experiences of the aesthetic aspects of the intervention via questionnaire, this area could be explored using more in-depth methodologies.

\section{STRENGTHS \& LIMITATIONS}

This study provides rich insights into the experience of real people undergoing psychological change as they interact with the technology. The study was conducted in a naturalistic setting and longitudinally across three timepoints, and the data were collected online, in the client's own time, which mediated desirability bias. Despite this, response bias is a concern. Other limitations include some priming in the questions, which was done to avoid overly literal responses e.g. the context question was 'When do you think you will use SilverCloud (this could be at particular times, situations, or moods for example)?'. Furthermore, the fact that only clients with complete data (answers to all ten questions) were included could have influenced the results.

\section{CONCLUSIONS}

Guided online therapy is a rich, many layered experience for clients. Factors extraneous to the intervention, including the systems and structures that surround the treatment and each individual client's level of motivation, readiness for change and hopefulness, have as much of an impact on the client's experience as the intervention itself. Exploring the many layered tensions that intersect the design of these technologies can help us to make informed decisions about how we mediate polarised elements such as flexibility and engagement. Our research indicates that clients are experiencing online interventions as lifestyle support systems which empower them to help themselves. Understanding how clients use and integrate these interventions in their lives can help us to design future technologies that go beyond traditional models of therapy, focusing instead on how we can leverage technology to effectively address client needs.

\section{ACKNOWLEDGEMENTS}

The research of Gavin Doherty is funded in part by SFI grant no. 13/RC/2106 to the Adapt Centre. 


\section{REFERENCES}

[1] F. E. M. de Alva, G. Wadley, and R. Lederman. 2015. 'It feels different from real life ': Users ' Opinions of Mobile Applications for Mental Health. In Proceedings of the Annual Meeting of the Australian Special Interest Group for Computer Human Interaction, 598-602. DOI:https://doi.org/10.1145/2838739.2838806

[2] Mikhail Mikhaulovich Bakhtin. 2010. Toward a Philosophy of the Act. University of Texas Press.

[3] Marguerite Barry, Kevin Doherty, Jose Marcano Bellisario, Josip Car, Cecily Morrison, and Gavin Doherty. 2017. mHealth for Maternal Mental Health : Everyday Wisdom in Ethical Design. In CHI '17: Proceedings of the 2017 CHI Conference on Human Factors in Computing Systems, 27082720.

[4] Angela Beattie, Alison Shaw, Surinder Kaur, and David Kessler. 2009. Primary-care patients expectations and experiences of online cognitive behavioural therapy for depression : a qualitative study. Heal. Expect. (2009), 45-59. DOI:https://doi.org/10.1111/j.13697625.2008.00531.x

[5] Ann Blandford, Jo Gibbs, Nikki Newhouse, Olga Perski, Aneesha Singh, and Elizabeth Murray. 2018. Seven lessons for interdisciplinary research on interactive digital health interventions. Digit. Heal. 4, (2018), 1-13. DOI:https://doi.org/10.1177/2055207618770325

[6] Cristina Botella, Giuseppe Riva, Andrea Gaggioli, Brenda K. Wiederhold, Mariano Alcaniz, and Rosa M. Baños. 2012. The Present and Future of Positive Technologies. Cyberpsychology, Behav. Soc. Netw. 15, 2 (2012), 78-84.

DOI:https://doi.org/10.1089/cyber.2011.0140

[7] John Burke, Derek Richards, and Ladislav Timulak. 2018. Helpful and Hindering Events in InternetDelivered Cognitive Behavioural Treatment for Generalized Anxiety. Behav. Cogn. Psychother. (2018). DOI:https://doi.org/10.1017/S1352465818000504

[8] Rafael A. Calvo and Dorian Peters. 2014. Positive Computing: Technology for wellbeing and human potential. MIT Press, Cambridge, London.

[9] B. Cludius, J. Schröder, and S. Moritz. 2018. Expectancy effects in self-help depression treatment: first evidence that the rationale given for an online study impacts the outcome. Behav. Cogn. Psychother. 46, 2 (2018), 195-208.

[10] P. Cuijpers, A. van Straten, P. van Oppen, and G. Andersson. 2008. Are psychological and pharmacologic interventions equally effective in the treatment of adult depressive disorders? A meta- analysis of comparative studies. J. Clin. Psychiatry (2008).

[11] John Dewey. 2005. Art as Experience. The Penguin Group, New York.

[12] Gavin Doherty, David Coyle, and Mark Matthews. 2010. Design and evaluation guidelines for mental health technologies. Interact. Comput. 22, 4 (2010), 243-252.

DOI:https://doi.org/10.1016/j.intcom.2010.02.006

[13] Gavin Doherty, David Coyle, and John Sharry. 2012. Engagement with Online Mental Health Interventions : An Exploratory Clinical Study of a Treatment for Depression. In Proceedings of the SIGCHI Conference on Human Factors in Computing Systems, 1421-1430.

[14] Kevin Doherty and Gavin Doherty. 2018. The Construal of Experience in HCI : Understanding Self-Reports. Int. J. Hum. Comput. Stud. (2018), 63-74.

DOI:https://doi.org/10.1016/j.jhcs.2017.10.006.the

[15] Liesje Donkin and Nick Glozier. 2012. Motivators and Motivations to Persist With Online Psychological Interventions : A Qualitative Study of Treatment Completers. J. Med. Internet Res. 14, 3 (2012). DOI:https://doi.org/10.2196/jmir.2100

[16] C Earley, C Joyce, J Mcelvaney, D Richards, and L Timulak. 2017. Preventing depression :

Qualitatively examining the benefits of depressionfocused iCBT for participants who do not meet clinical thresholds. Internet Interv. 9, July (2017), 82-87.

DOI:https://doi.org/10.1016/j.invent.2017.07.003

[17] J Fernández-álvarez, A Díaz-garcía, A Gonzálezrobles, R Baños, and A García-palacios. 2017. Dropping out of a transdiagnostic online intervention: A qualitative analysis of client' $s$ experiences. Internet Interv. 10, May (2017), 2938.

DOI:https://doi.org/10.1016/j.invent.2017.09.001

[18] Theresa Fleming, Lynda Bavin, Mathijs Lucassen, Karolina Stasiak, Sarah Hopkins, and Sally Merry. 2018. Beyond the trial: Systematic review of realworld uptake and engagement with digital self-help interventions for depression, low mood, or anxiety. J. Med. Internet Res. 20, 6 (2018), 1-11. DOI:https://doi.org/10.2196/jmir.9275

[19] Jodi Forlizzi and Katja Battarbee. 2004. Understanding Experience in Interactive Systems. In Proceedings of the 5th conference on Designing interactive systems: processes, practices, methods, and techniques, 261-268.

[20] Jodi Forlizzi and Shannon Ford. 2000. The Building Blocks of Experience : An Early Framework for 
Interaction Designers. In Proceedings of the 3rd conference on Designing interactive systems: processes, practices, methods, and techniques.

[21] Lina Gega, Joanna Smith, and Shirley Reynolds. 2013. Cognitive behaviour therapy ( CBT ) for depression by computer vs . therapist : Patient experiences and therapeutic processes. Psychother. Res. 23, 2 (2013).

[22] S. A. H. Gerhards, T. A. Abma, A. Arntz, L. E. De. Graaf, S. M. A. A. Evers, M. J. H. Huibers, and G. A. M. Widdershoven. 2011. Improving adherence and effectiveness of computerised cognitive behavioural therapy without support for depression: A qualitative study on patient experiences. J. Affect. Disord. 129, 1-3 (2011), 117-125.

DOI:https://doi.org/10.1016/j.jad.2010.09.012

[23] Franz Gravenhorst, Amir Muaremi, Jakob Bardram, Agnes Grunerbl, Oscar Mayora, Gabriel Wurzer, Mads Frost, Venet Osmani, Bert Arnrich, Paul Lukowicz, and Gerhard Troster. 2015. Mobile phones as medical devices in mental disorder treatment: an overview. Pers. Ubiquitous Comput. 19, 2 (2015), 335-353.

DOI:https://doi.org/10.1007/s00779-014-0829-5

[24] Marc Hassenzahl. 2004. The Interplay of Beauty, Goodness, and Usability in Interactive. HumanComputer Interact. 19, (2004), 319-349. DOI:https://doi.org/10.1207/s15327051hci1904

[25] Kristin E Heron and Joshua M Smyth. 2010. Ecological momentary interventions: incorporating mobile technology into psychosocial and health behaviour treatments. Br. J. Health Psychol. 15, Pt 1 (2010), 1-39. DOI:https://doi.org/10.1348/135910709X466063

[26] Victoria Hollis, Artie Konrad, Aaron Springer, Matthew Antoun, Christopher Antoun, Rob Martin, and Steve Whittaker. 2017. What Does All This Data Mean for My Future Mood? Actionable Analytics and Targeted Reflection for Emotional Well-Being. Human-Computer Interact. 32, 5-6 (2017), 208-267.

DOI:https://doi.org/10.1080/07370024.2016.12777 24

[27] Anna Holst, Shabnam Nejati, Cecilia Björkelund, Maria C M Eriksson, Dominique Hange, Marie Kivi, Carl Wikberg, and Eva-lisa Petersson. 2017. Patients ' experiences of a computerised self-help program for treating depression - a qualitative study of Internet mediated cognitive behavioural therapy in primary care. Scand. J. Prim. Health Care 35, 1 (2017), 46-53. DOI:https://doi.org/10.1080/02813432.2017.12888 13
[28] Mahsa Honary and Fiona Lobban. 2018. Designing Video Stories Around the Lived Experience of Severe Mental Illness. In Proceedings of the 10th Nordic Conference on Human-Computer Interaction, 25-38.

[29] Ellen Isaacs, Artie Konrad, Alan Walendowski, Thomas Lennig, Victoria Hollis, and Steve Whittaker. 2013. Echoes From the Past: How Technology Mediated Reflection Improves WellBeing. In Proceedings of the SIGCHI conference on human factors in computing systems (pp. 10711080). ACM., 1071-1080.

[30] Daniel Kahneman, Barbara L Fredrickson, Charles A Schreiber, and Donald A Redelmeier. 1993. When More Pain Is Preferred To Less: Adding a Better End. Psychol. Sci. 4, 6 (1993). DOI:https://doi.org/10.1111/j.14679280.1993.tb00589.X

[31] Evangelos Karapanos, John Zimmerman, Jodi Forlizzi, and Jean-bernard Martens. 2009. User Experience Over Time : An Initial Framework. In Proceedings of the SIGCHI conference on human factors in computing systems, 729-738.

[32] Saskia Kelders, Robin Niels Kok, Hans Ossebaard, and J. E. W. C van Gemert-Pijnen. 2012. Persuasive System Design Does Matter : A Systematic Review of Adherence to Web-Based Interventions. J. Med. Internet Res. 14, 6 (2012). DOI:https://doi.org/10.2196/jmir.2104

[33] Saskia M Kelders, Ernst T Bohlmeijer, and Julia EWC Van Gemert-Pijnen. 2013. Participants , Usage, and Use Patterns of a Web-Based Intervention for the Prevention of Depression Within a Randomized Controlled Trial Corresponding Author: J. Med. Internet Res. 15, 8 (2013). DOI:https://doi.org/10.2196/jmir.2258

[34] Sarah E Knowles, Karina Lovell, Peter Bower, Simon Gilbody, Elizabeth Littlewood, and Helen Lester. 2015. Patient experience of computerised therapy for depression in primary care. BMJ Open (2015). DOI:https://doi.org/10.1136/bmjopen-2015008581

[35] Robert Kohn, Shekhar Saxena, Itzhak Levav, and Benedetto Saraceno. 2004. The treatment gap in mental health care. Bull. World Health Organ. 82, 11 (2004), 858-866.

[36] R. Lederman, G. Wadley, J. Gleeson, S. Bendall, and M. Álvarez-Jiménez. 2014. Moderated Online Social Therapy: Designing and Evaluating Technology for Mental Health. ACM Trans. Comput. Interact. 21, 1 (2014), 1-26.

[37] Heidi M Levitt, Andrew Pomerville, and Francisco I Surace. 2016. A Qualitative Meta-Analysis Examining Clients' Experiences of Psychotherapy : 
A New Agenda. Psychol. Bull. 142, 8 (2016), 801830.

[38] Deborah Lupton. 2014. Beyond Techno-Utopia: Critical Approaches to Digital Health Technologies. Societies 4, (2014), 706-711. DOI:https://doi.org/10.3390/soc4040706

[39] M. Magni, M. S. Taylor, and V. Venkatesh. 2010. 'To play or not to play': A cross-temporal investigation using hedonic and instrumental perspectives to explain user intentions to explore a technology. Int. J. Hum. Comput. Stud. 68, 9 (2010), 572-588.

[40] J. McCarthy and P. Wright. 2004. Technology as Experience. The MIT Press, Cambridge, Massachusetts. DOI:https://doi.org/10.1145/1015530.1015549

[41] Kathryn McHugh, Sarah W. Whitton, Andrew D. Peckham, Jeffrey A. Welge, and Michael W. Otto. 2013. Patient Preference for Psychological vs. Pharmacological Treatment of Psychiatric Disorders: A Meta-Analytic Review. J. Clin. Psychiatry 74, 6 (2013), 595-602. DOI:https://doi.org/10.4088/JCP.12r07757.Patient

[42] William R Miller and Stephen Rollnick. 2004. Talking Oneself Into Change : Motivational Interviewing, Stages of Change, and Therapeutic Process. J. Cogn. Psychother. An Int. Q. 18, 4 (2004), 2004.

[43] David C Mohr, Stacey L Hart, Isa Howard, Laura Julian, Lea Vella, Claudine Catledge, and Mitchell D. Feldman. 2006. Barriers to Psychotherapy among Depressed and Nondepressed Primary Care Patients. Ann. Behav. Med. 32, 3 (2006), 254-258. DOI:https://doi.org/10.1207/s15324796abm3203

[44] National Institute for Health and Care Excellence. 2009. The treatment and management of depression in adults. Clinical guideline [CG90]. London: UK. Retrieved from https://www.nice.org.uk/guidance/cg90

[45] Janine V Olthuis, Margo C Watt, Kristen Bailey, Jill A Hayden, and Sherry H Stewart. 2015.

Therapist-supported Internet cognitive behavioural therapy for anxiety disorders in adults. Cochrane Database Syst. Rev. January (2015). DOI:https://doi.org/10.1002/14651858.CD011565

[46] Ramesh P Perera-delcourt and Gemma Sharkey. 2019. Patient experience of supported computerized CBT in an inner-city IAPT service : a qualitative study. Cogn. Behav. Ther. 12, e13 (2019), 1-23. DOI:https://doi.org/10.1017/S1754470X18000284

[47] James O. Prochaska, Colleen A. Redding, and Kerry E. Evers. 2015. The transtheoretical model and stages of change. In Health behavior: Theory, research, and practice. 97.

[48] Chengcheng Qu, Corina Sas, and Gavin Doherty. 2019. Exploring and Designing for Memory Impairments in Depression. In Proceedings of the 2019 CHI Conference on Human Factors in Computing Systems, 1-14.

[49] Stefan Rennick-Egglestone, Sarah Knowles, Gill Toms, Penny Bee, Karina Lovell, and Pete Bower. 2016. Health Technologies ' In the Wild ': Experiences of Engagement with Computerised CBT. Proc. 2016 CHI Conf. Hum. Factors Comput. Syst. 2016, May (2016), 2124-2135.

[50] J. Richards, D., Enrique, E., \& Palacios. 2019. Internet-delivered cognitive behaviour therapy. In The Handbook of Brief Therapies: A Practical Guide, S. Parry (ed.). SAGE, 248.

[51] Derek Richards, Mairead Dowling, Emma O'Brien, Noemi Vigano, and Ladislav Timulak. 2018. Significant events in an Internet-delivered ( Space from Depression ) intervention for depression. Couns. Psychother. Res. 18, 1 (2018), 35-48. DOI:https://doi.org/10.1002/capr.12142

[52] Derek Richards, Daniel Duffy, Brid Blackburn, Caroline Earley, Angel Enrique, Jorge Palacios, Matthew Franklin, Gabriella Clarke, Sarah Sollesse, Sarah Connell, and Ladislav Timulak. 2018. Digital IAPT : the effectiveness \& cost- effectiveness of internet-delivered interventions for depression and anxiety disorders in the Improving Access to Psychological Therapies programme : study protocol for a randomised control trial. $B M C$ Psychiatry 18, 1 (2018), 59.

[53] Derek Richards, L Timulak, E O'Brien, C Hayes, N Vigano, J Sharry, and G Doherty. 2015. A randomized controlled trial of an internet-delivered treatment : Its potential as a low-intensity community intervention for adults with symptoms of depression. Behav. Res. Ther. 75, (2015), 20-31. DOI:https://doi.org/10.1016/j.brat.2015.10.005

[54] Derek Richards and Ladislav Timulak. 2012. Client-identified helpful and hindering events in therapist-delivered vs . self-administered online cognitive- behavioural treatments for depression in college students. Couns. Psychol. Q. August 2012 (2012), 37-41. DOI:https://doi.org/10.1080/09515070.2012.70312 9

[55] Giuseppe Riva, Rosa M. Baños, Cristina Botella, Brenda K. Wiederhold, and Andrea Gaggioli. 2012. Positive Technology: Using Interactive Technologies to Promote Positive Functioning. Cyberpsychology, Behav. Soc. Netw. 15, 2 (2012), 69-77.

DOI:https://doi.org/10.1089/cyber.2011.0139 
[56] D. A. Rohani, N. Tuxen, A. Q. Lopategui, M. Faurholt-Jepsen, L. V. Kessing, and J. E. Bardram. 2019. Personalizing Mental Health : A Feasibility Study of a Mobile Behavioral Activation Tool for Depressed Patients. In Proceedings of the 13th EAI International Conference on Pervasive Computing Technologies for Healthcare, 282-291.

[57] Theresia Rost, Janine Stein, Margrit Löbner, Anette Kersting, Claudia Luck-Sikorski, and Steffi G Riedel-Heller. 2017. User Acceptance of Computerized Cognitive Behavioral Therapy for Depression : Systematic Review. J. Med. Internet Res. 19, (2017), 1-13.

DOI:https://doi.org/10.2196/jmir.7662

[58] Sune Rubak, Annelli Sandbæk, Torsten Lauritzen And, and Bo Christensen. 2005. Motivational interviewing : a systematic review and metaanalysis. Br. J. Gen. Pract. April (2005), 305-312.

[59] Pedro Sanches, Pavel Karpashevich, Gavin Doherty, Axel Janson, Charles Windlin, Corina Sas, Camille Nadal, and Kristina Höök. 2019. HCI and Affective Health Taking stock of a decade of studies and charting future research directions. In Proceedings of the 2019 CHI Conference on Human Factors in Computing Systems, 245.

[60] R. C. Schank. 1995. Tell me a story: Narrative and intelligence. Northwestern University Press, Evanston, Illinois.

[61] Justine Schneider, Pooria Sarrami Foroushani, Paul Grime, and Graham Thornicroft. 2014.

Acceptability of Online Self-Help to People With Depression : Users' Views of MoodGYM Versus Informational Websites. J. Med. Internet Res. 16, 3 (2014). DOI:https://doi.org/10.2196/jmir.2871

[62] Stephen M Schueller and David C Mohr. 2015. Initial Field Trial of a Coach-Supported Web-Based Depression Treatment. In International Conference on Pervasive Computing Technologies for Healthcare.

DOI:https://doi.org/10.4108/icst.pervasivehealth.20 15.260115

[63] C R Snyder. 2002. Hope Theory: Rainbows in the Mind. Psychol. Inq. 13, 4 (2002), 249-275.

[64] Aaron Springer, Victoria Hollis, and Steve Whittaker. 2018. Mood Modeling : Accuracy Depends on Active Logging and Reflection. Pers. Ubiquitous Comput. 22, 4 (2018), 723-737. DOI:https://doi.org/https://doi.org/10.1007/s00779018-1123-8

[65] Katarzyna Stawarz, Chris Preist, Debbie Tallon, Nicola Wiles, and David Coyle. 2018. User Experience of Cognitive Behavioral Therapy Apps for Depression : An Analysis of App Functionality and User Reviews. J. Med. Internet Res. 20, 6
(2018).

[66] Deborah Tatar. 2007. The Design Tensions Framework. Human-Computer Interact. 22, (2007), 413-451.

[67] Anja Thieme, Jayne Wallace, Thomas D Meyer, and Patrick Olivier. 2015. Designing for Mental Wellbeing : Towards a More Holistic Approach in the Treatment and Prevention of Mental Illness. In Proceedings of the 2015 British HCI Conference, $1-10$.

[68] Ladislav Timulak. 2007. Identifying core categories of client-identified impact of helpful events in psychotherapy: A qualitative meta-analysis. Psychother. Res. 17, May (2007), 310-321. DOI:https://doi.org/10.1080/10503300600608116

[69] Ladislav Timulak and Robert Elliott. 2019. Taking stock of descriptive - interpretative qualitative psychotherapy research : Issues and observations from the front line. Couns. Psychother. Res. 19, 1 (2019), 8-15.

DOI:https://doi.org/10.1002/capr.12197

[70] Noam Tractinsky and Dror Zmiri. 2006. Exploring Attributes of Skins as Potential Antecedents of Emotion in HCI. In Aesthetic computing, P. Fishwick (ed.). MIT Press, Cambridge, 405-422.

[71] Nash Unsworth. 2016. Working Memory Capacity and Recall From Long-Term Memory : Examining the Influences of Encoding Strategies, Study Time Allocation, Search Efficiency, and Monitoring Abilities. J. Exp. Psychol. Learn. Mem. Cogn. 42, 1 (2016), 50-61.

[72] Daniel Vigo, Graham Thornicroft, and Rifat Atun. 2016. ESTIMATING THE TRUE GLOBAL BURDEN OF MENTAL ILLNESS. Lancet Psychiatry 3, 2 (2016), 171-178.

[73] Q. Wang. 2016. Remembering the self in cultural contexts: A cultural dynamic theory of autobiographical memory. Mem. Stud. 9, 3 (2016), 295-304.

[74] Henny A Westra and David J A Dozois. 2006. Preparing Clients for Cognitive Behavioral Therapy: A Randomized Pilot Study of Motivational Interviewing for Anxiety. Cognit. Ther. Res. 30, 4 (2006), 481-498. DOI:https://doi.org/10.1007/s10608-006-9016-y

[75] H.A. Whiteford, L. Degenhardt, J. Rehm, A.J. Baxter, A.J. Ferrari, H.E. Erskine, F.J. Charlson, R.E. Norman, A.D. Flaxman, N. Johns, and R Burstein. 2013. Global burden of disease attributable to mental and substance use disorders: findings from the global burden of disease study 2010. Lancet 382, 9904 (2013), 1575-86.

[76] Maja Wilhelmsen, Kjersti Lillevoll, Mette Bech 
Risør, Ragnhild Høifødt, May-lill Johansen, Knut Waterloo, Martin Eisemann, and Nils Kolstrup. 2013. Motivation to persist with internet-based cognitive behavioural treatment using blended care : a qualitative study. BMC Psychiatry 13, (2013), 296.

[77] Cara Wilson, Steve Draper, Margot Brereton, and Daniel Johnson. 2017. Towards Thriving : Extending Computerised Cognitive Behavioural Therapy. In Proceedings of the 29th Australian Conference on Computer-Human Interaction, 285295.
[78] J.H. Wright, J.J. Owen, D. Richards, T.D. Eells, T. Richardson, G.K. Brown, M. Barrett, M.A. Rasku, G. Polser, and M.E. Thase. 2019. ComputerAssisted Cognitive-Behavior Therapy for Depression: A Systematic Review and MetaAnalysis. J. Clin. Psychiatry 80, 2 (2019).

[79] A. S. Young, R. Klap, C. D. Sherbourne, and K. B. Wells. 2001. The quality of care for depressive and anxiety disorders in the United States. Arch. Gen. Psychiatry 58, 1 (2001), 55-61. 